\title{
Energy problems of the rational use of the economic potential of the region
}

\author{
N. Danilov ${ }^{1}$, V. Silin ${ }^{1}$, V. Dobrodey ${ }^{2} \&$ V. Popov ${ }^{2}$ \\ ${ }^{I}$ The Ural Federal University named after the first President of Russia \\ B. N. Yeltsin, Russia \\ ${ }^{2}$ The State Budget Institution of Sverdlovsk Region \\ "Institute of Energy Saving", Russia
}

\begin{abstract}
Analysis of problems of the social-economic development of the region, the assessment of the regional economy from the position of the full and rational use of its economic potential supposes developing an appropriate system of special indices, creating tools for their quantitative characteristics. Economic resources as basic constraints for regional economic development are of paramount importance. It is known that these are non-renewable natural, in particular, fuel and energy resources. State authorities at a federal and regional level play an essential role in the regulation of competitive access to energy resources in Russia. The using of balance sheet methods for analysing and comparing different ways of economic development of the areas, the corresponding demand for fuel and energy resources, regulating the export and import of fuel and energy resources, assessing the impact of energy efficiency programs and energy efficiency in the power settings are provided at the legislative level. The paper describes some results and conclusions derived from studies using different approaches to forming a regional energy balance model based on the data of the Sverdlovsk region.

Keywords: model, forecast, energy efficiency, gross regional product, fuel and energy balance.
\end{abstract}

\section{Introduction}

The natural consequence of the fuel and energy resources (FER) deficit is a toughening of competition for access to energy resources between both 
commodity producers and regions. To quantify the impact of the deficit on the use of energy resources potential of the region is necessary to develop adequate economic and mathematical models based on different concepts combining constructive economic space - geographic, geopolitical and others. Taken together, these concepts suggest the possibility of relative territorial localization of the economic space that not necessarily coincides with the administrative boundaries of the region. Relevance of research in this area is determined by increasing impact of energy efficiency in economy on the competitive positions of Russian producers, the necessity to maintain energy security of areas and to prevent social and industrial crises. In adopting measures of state regulation it is focused on the development of fuel and energy balance (FEB) models: improving their conjugation with special power indicators, extending of assessment possibilities of its ecological characteristics and financial accessibility, of energy resources for consumers, accounting of the structural features of the regional economic process. Empirical calculations based on data of the Sverdlovsk region confirm the expediency disintegration of energy consumption according to types of economic activity - thereby the selfdescriptiveness of energy balance and its matching to the format data of Rosstat increase. The article analyses the methodological and informational problems emerging in the formation of the energy balance on the administrative level of regions [1].

\section{Information and technological problems of formation of current and forecast energy balance of the region}

Constructive analysis and forecasting of territorial power consumption require a holistic approach taking into account the objective unity and interrelation of all the essential elements and aspects of the reproductive process. It is known that the balanced methods, historically arising from the practice needs of economic management can provide the most complete implementation of this approach. This has led to their widespread use in the social and economic development programs, to substantiate State policy on energy saving and energy efficiency of the economy. Appropriate models are based on the advanced application software that allows approximating the regional economic process dynamics. Using of balanced methods of economic management supposes information that describes the perspective structure of the resulting needs of the territory as a whole and individual industries and actors of the regional market of FER. However, the reliability of statistical information in a market economy is greatly reducing.

The methodology, that applied in the research within Sverdlovsk region to reflect the relations between the integral characteristics, size of gross regional product (GRP) and its energy intensity indicators, the balance of inter-regional flows of energy resources, assessment of the total energy savings and energy efficiency, etc.), is based on a combination of economic identities and their stochastic elements - output volume and energy production (works, services), projections of turnover, gross output, intermediate consumption and value added 
of basic economic activities. The indicative scenario approach based on the use of statistical methods of data, on analytic and expert assessments of the expected parameters of corporate and territorial programs got a preference. The FEB structure also reflects the volumes of major (energy-intensive) output of products (works, services) that is also determined by means of methodological and legal requirements for the correctness of reflection of the current and projected energy consumption processes. However, representation of the structure of fuel consumption only in the form of a unit "product" block causes the serious information and methodological difficulties in formation of reported FEB, and the complexity of problems increases when justifying predictive options. We cannot solve the address less FER consumption in the framework of the "product" concept. Such "white spots" are formulating as "other consumption" (it can be more than $25 \%$ of total electricity and heat consumption). Statistics for some types of economic activities, such as education, medicine and health, legal and banking services, and other energy-intensive range of products and services is not represented.

\section{Adapting regional structure of fuel and energy balance System of National Accounts}

The modernized structure of the fuel and energy balance (named below "FEB SNA") in the Sverdlovsk region calculations was used in order to assess the impact of basic economic activities on the GRP energy intensity of the Sverdlovsk region. The analysis of energy efficiency dynamics in every sector of the economy with taking into account the estimate contribution of the GRP volume allowed investigating the conditions of the Program of socio-economic development of the Sverdlovsk region in 2012-2015 years more deeply, scenarios for the forecast for the period FEB 2013-2016 and up to 2020 were developed. An Implantation of the basic ("clean") types of economic activities conforms to the principle of separating out of structural core that defines the basic parameters of the dynamics of power consumption and general framework conditions of the functional consistency of the analysed scenario. The detailing of these conditions through the product block (works, services) allows assessing the important additional quality of balance characteristics. Evaluation of the regional demand for energy resources in the framework of FEB SNA concept is being reflected through the following formal relations for clean economic activities (index i) and the conditional fixed period of 2010-2015 (eqn. (1)).

$$
y_{i t}=y_{i}^{\text {base }} q_{i t}, i \in \overline{1, m} ; t \in\{2010 ; 2015\}
$$

$\boldsymbol{y}_{\boldsymbol{i}}, y_{i}^{\text {base }}$ value added type $\boldsymbol{i}$ of base and forecast year $\boldsymbol{t} ; \boldsymbol{q}_{\boldsymbol{i t}}$ - scenario rate of changing of its physical volumes to the base year; $t$ - forecast year ; indicators of specific energy consumption, heat consumption and fuel in the base year (vector of energy consumption). Demand for electricity $(j=1)$, thermal energy $(j=2)$, and the total fuel demand (index f) in the base year (eqn. (2)): 
422 Energy Production and Management in the 21st Century, Vol. 1

$$
A_{i 1}^{\text {base }}=a_{i 1}^{\text {base }} y_{i}^{\text {base }}, A_{i 2}^{\text {base }}=a_{i 2}^{\text {base }} y_{i}^{\text {base }}, A_{i f}^{\text {base }}=a_{i f}^{\text {base }} y_{i}^{\text {base }},
$$

We put in correspondence the range of types of fuel consumed, $j=3,4, \ldots, n$ (both individual FER) to Index $\mathrm{f}$. Then the structure of demand for fuel in the base year $A_{i j}^{\text {base }}$ and its proportions $A_{i j}^{\text {base }}$ is determined from the relationship (eqn. (3)):

$$
A_{i j}^{\text {base }}=a_{i j}^{\text {base }} y_{i}^{\text {base }}, \lambda_{i j}^{\text {base }}=\frac{A_{i j}^{\text {base }}}{A_{i f}^{\text {base }}}, j \in \overline{3, n} ; i \in \overline{1, m} .
$$

Fuel capacity of certain fuels in the base year. The vector components of energy consumption perspective (eqn. (4))

$$
a_{i 1 t}=a_{i 1}^{\text {base }} r_{i 1 t}, a_{i 2 t}=a_{i 2}^{\text {base }} r_{i 2 t}, a_{i f t}=a_{i f}^{\text {base }} r_{i f t}, i \in \overline{1, m} ; t \in\{2010,2015\}
$$

where $r_{i l t}, r_{i 2 t}, r_{i f t}$ - the rate of change of energy intensity in year $t$ relative to baseline values Scenario demand for energy resources by type of activity and its detailing (eqn. (5)):

$$
\begin{aligned}
& A_{i 1 t}=a_{i 1 t} y_{i t}, A_{i 2 t}=a_{i 2 t} y_{i t}, A_{i f t}=a_{i f t} y_{i t}, A_{i j t}=a_{i j t} y_{i t}=A_{i f t} \lambda_{i j}^{\text {base }} ; \\
& j \in \overline{3, n} ; i \in \overline{1, m} ; t \in\{2010 ; 2015 \ldots\}
\end{aligned}
$$

Specific losses of electricity, heat and gas in transmission and distribution networks, and the dynamics of their declining are similarly accounted. To determine the volume of supply of electricity is needed to account the recursive connections between private balance sheets (eqn. (6)).

$$
\bar{A}_{j t}=A_{j t}+\bar{S}_{j t}=A_{j t}+k_{j t} \bar{A}_{j t}=\frac{1}{1-k_{j t}} A_{j t}, t \in\{2010,2015\}, j=1,2
$$

$\bar{A}_{j t}-$ FER required volume of delivery in the network; $A_{j t}-$ projected total demand for FER; $\bar{S}_{j t}-$ FER loss in backbone networks; $k_{i j}$ - specific losses in networks; $\boldsymbol{j}$ - FER index.

The additional factors that determine a rationality of changes in the FEB concept as well as other similar models are informational. The lack of types of economic activities in the FEB structure makes difficulties in the balance procedures, interval (indicative) prediction, evaluation and analysis of the major integral characteristics of FEB and their dynamics.

The model of FEB SNA supposes the calculating of indicators for certain types of economic activity. Such a representation of forecasts allows reflecting objectively existing interdependence between the dynamics and structure of the regional economy as a whole and its individual production and activities. FEB SNA structure also largely corresponds to the approved special indicators of regional economic development programs. 
Practical application of the FEB SNA model in calculations for the Sverdlovsk region revealed the dynamics of the most important private and general indicators of energy consumption during 2007-2012 period and implement their forecast, fig. 1. The possibility to realize industrial production indices of the Sverdlovsk region in according to the forecast supposes of carrying out some innovative programs (in particular, the State Program of Sverdlovsk Region "The development of industry and science in the Sverdlovsk region till 2020 year").

According to the calculation, energy intensity of GRP of the Sverdlovsk region in 2007 was 48.4 t.s.f./ million rubles at 2007 prices (t.s.f - ton of standard fuel). In 2017, the energy intensity of gross regional product is expected to reach 32.79-32.98 t.s.f./ million rubles, which is below the level in 2016 by $4.0-4.1 \%$ below the 2007 level of $31.9-32.3 \%$ in 2007 prices. In the period from 2017 to 2020 projected average annual reduction in energy intensity of $3.8-4.0 \%$ per year. Energy intensity of GRP by 2020 is projected around 29.05-29.50 t.s.f./ million rubles, amounting to $60.0-60.9 \%$ of the 2007 level (fig. 1).

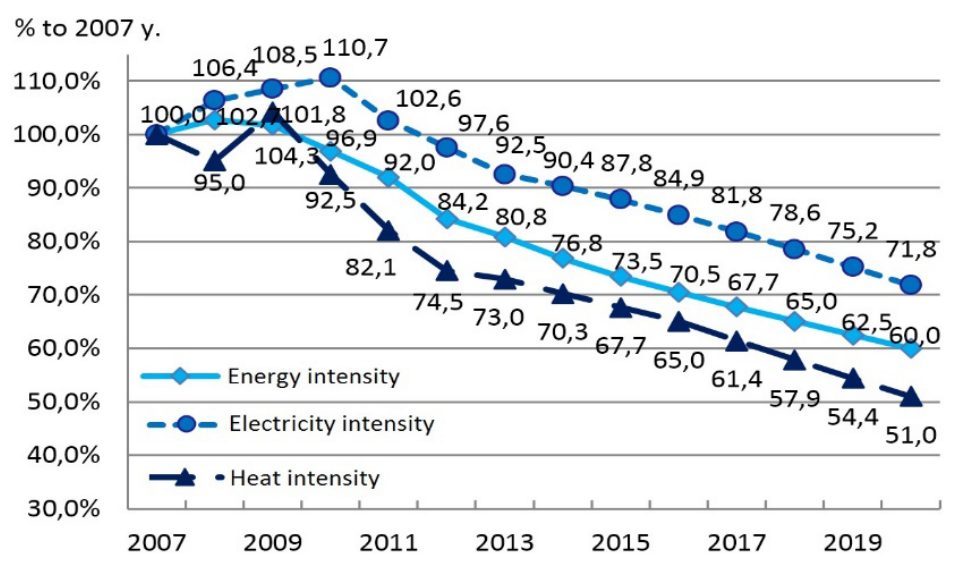

Figure 1: Dynamics of energy intensity of GRP, electricity intensity of GRP and heat intensity of GRP in Sverdlovsk region under the optimistic scenario.

It should be noted that the implementation of RF President's task to reduce the GDP energy intensity of the Russian Federation not less than 40 per cent by 2020 compared with 2007 is predicted only of the optimistic scenarios of socio economic development.

\section{Reference}

[1] Order of the Ministry of Energy of 14.12.2011 N 600 "On approval of drawing energy balances of the Russian Federation and municipalities" (Registered in the Ministry of Justice on 01.02.2012 N 23101) 